\title{
Sensory Attributes of Three Edible Tropical Mushrooms and Their Use in Formulating Food Products for Children 2-5 Years Old
}

\author{
Hagan Lynda Larmkie ${ }^{1}$, Johnson Paa-Nii Torgbor ${ }^{2, *}$, Obodai Mary ${ }^{1,2}$, Blay Adjei Maame Yaa ${ }^{3}$, \\ Simons Christopher ${ }^{4}$, Dzomeku Matilda ${ }^{1}$ \\ ${ }^{1}$ CSIR-Food Research Institute, Accra, Ghana \\ ${ }^{2}$ Department of Agro-processing Technology and Food Biosciences, CSIR-College of Science and Technology, Accra, Ghana \\ ${ }^{3}$ Department of Nutrition and Food Science, University of Ghana, Accra, Ghana \\ ${ }^{4}$ Department of Food Science and Technology, The Ohio State University, Colombus, USA
}

Email address:

lawerlarmikie@yahoo.com (H. L. Larmkie), paanii.johnson@gmail.com (J. Paa-Nii T.), obodaime@yahoo.com (O. Mary), myblay@ug.edu.gh (B. A. M. Yaa), simons.103@osu.edu (S. Christopher), matildadela@yahoo.com (D. Matilda)

${ }^{*}$ Corresponding author

\section{To cite this article:}

Hagan Lynda Larmkie, Johnson Paa-Nii Torgbor, Obodai Mary, Blay Adjei Maame Yaa, Simons Christopher, Dzomeku Matilda. Sensory Attributes of Three Edible Tropical Mushrooms and Their Use in Formulating Food Products for Children 2-5 Years Old. International Journal of Nutrition and Food Sciences. Vol. 7, No. 3, 2018, pp. 100-109. doi: 10.11648/j.jinfs.20180703.14

Received: April 5, 2018; Accepted: April 28, 2018; Published: May 25, 2018

\begin{abstract}
Background: Mushrooms are important sources of proteins and vitamins, but have unique sensory properties in appearance, flavour and texture that can lead to polarized liking amongst consumers. Children between the ages of 2 to 5 years can be picky eaters and adding vegetables such as mushrooms into their diets can be a challenge. Objective: This study involved the development of mushroom-based food products acceptable to children within this age bracket through a stepwise approach. Materials and Methods: Sensory attributes of three tropical edible mushrooms, Pleurotus ostreatus (EMI), Pleurotus sajor-caju (PSCW) and Auricularia ssp. (ART), were characterized using quantitative descriptive analysis (QDA), using 30 descriptors. The QDA revealed that all three mushrooms differ distinctly from each other in appearance, mouthfeel and aftertaste. The aroma and flavour profiles of EM1 and PSCW mushrooms were comparable. From the QDA, EMI and PSCW were selected and used to formulate six mushroom-based food prototypes; three of which included cereals and the other three had orange-flesh yellow potato flour as main components. The 6 prototype foods were then assessed by three sets of focus groups of caregivers and mothers on the suitability of using the mushrooms in the preparation of foods for children of the target age. Two mushroom-based food products, one with cereal blends and the other with $30 \%$ orange flesh yellow potato flour were further subjected to consumer-liking tests involving 83 children 2-5 years old. and this final test established the mushrooms can be incorporated into children's diet. Conclusion: The study established two of the mushrooms could be used as flavourant; EMI mushroom suitable for fish or savory-flavoured products whilst the PSCW mushroom was preferred for nuttyflavoured products and these two when used in mushroom-based foods were highly acceptable to children 2 to 5 year old.
\end{abstract}

Keywords: Edible Tropical Mushrooms, Sensory Attributes, Consumer-Linking Test, Children Aged 2-5 Years

\section{Introduction}

In most forests areas in Ghana, wild edible mushrooms are regularly collected when in season and used directly as a main source of food or added to dishes such as soups, stews, and teas to enhance flavour and texture. Recently, edible mushrooms have attracted much interest as functional foods because of their anti-mutagenic, anti-tumoral and anti-viral properties. There are at least 270 species of mushrooms that are known to possess medicinal properties, and regular consumption has potential to benefit an individual's diet. A recent ethno-mycological study conducted in the southern 
part of Ghana revealed thirty different mushrooms were collected by consumers, with Volvariella volvacea, Termitomyces sp., Coprinus disseminates, Pleurotus tuberregium, Ganoderma lucidum, Coprinus disseminatus, Schizophyllum commune and Daldinia concentrica being the most used for consumption. [3, 4], Generally, mushrooms are anecdotally thought to reduce obesity, promote weight gain in underweight children, treat asthma, lower blood pressure in hypertensive patients, treat rheumatism, treat diarrhoea and other conditions. It is well acknowledged that underweight, stunting and thinness are serious and widespread nutritional disorders affecting an estimated $16 \%$ of young children globally from 2005-2011 and these effects can be reduced through proper nutrition. [7, 8]. The situation is even dire among children Ghana 2 to 5 years old. Attempts at solving the mal-nutritional problems in children have for some time now focused on using cereal and legume blends to produce high quality, high protein infant foods. Unfortunately, these solutions can be costly and efforts are needed to identify alternatives that use fewer of farmers' resources in disadvantaged and poor-resourced communities in Africa.

Given its rich nutrient sources, mushrooms present a unique alternative to the current efforts. They can easily be cultivated using organic agricultural wastes, which are abundant in Ghana and throughout Africa. To introduce children to diets regularly incorporated with mushrooms may require special efforts, given that children between the age groups 2 to 5 are not keen to accept vegetables in the diets. [11], Children at this stage tend to selective on what foods they like and what they do not like. Getting children to eat nutritious foods can be challenging for mothers and caregivers. There are a wide range of mushrooms with different sensory properties that could provide a rich source of proteins, minerals and fibre. Studies have shown that incorporating consumer insight in the early stages and throughout the development process of food products gives a better chance of success on the market. The objective of this study was therefore to investigate how the sensory attributes of some edible tropical mushroom influence the development of mushroom-based products for children within the age group 2-5 years.

\section{Materials and Methods}

This study began with using Quantitative Descriptive Analysis (QDA) in order to understand the sensory properties of the three edible mushrooms (Pleurotus ostreatus (EMI), Pleurotus sajor-caju (PSCW) and Auricularia ssp. (ART). This exercise was immediately followed by three focus groups discussions (FGD) involving mothers and caregivers in order to assess their perceptions and attitudes towards using mushrooms in preparing foods for children of age between 2 and 5 years old and finally a consumer-liking test involving 83 preschool children of the target age.

\subsection{Description of the Preparation of the Mushroom-Based Food Samples Used in the Study}

Two different mushroom- based products were used in the QDA and the FGD. These are briefly described below.

\subsubsection{Preparation of Mushroom Powder Slurry for the QDA}

Freshly harvested samples of the three edible mushrooms, Pleurotus ostreatus (EMI), Pleurotus sajor-caju (PSCW) and Auricularia ssp. (ART), were air-dried at $45 \pm 2{ }^{\circ} \mathrm{C}$ for $9 \mathrm{~h}$ to a moisture content $5 \%$, milled into powder and stored in sealed polythene bags and kept in a refrigerator until ready for analysis. To carry out the QDA, slurries of each powdered mushroom were prepared by thoroughly mixing $15 \mathrm{~g}$ of the powder in $300 \mathrm{ml}$ of freshly boiled hot water. The slurries were stored in a thermos flask and kept warm at $60^{\circ} \mathrm{C}$.

\subsubsection{Preparation of Mushroom-Based Food Products for the FGD}

Six mushroom-based food products were prepared for the FGD. Two of these six had cereal blends, referred to as Mushroom Cereal Blends (MCB) foods, whilst the other four had orange flesh potatoes (MOFSP), as the main component.

The Mushroom Cereal Blends food products (MCB) used rice, soybean, peanut and mushrooms (EM1 and PSCW). The rice grains were cleaned, sorted and roasted for 15 min under low heat in an oven until golden yellow and allowed to cool before use. Peanuts were also cleaned, sorted and roasted in an oven at $190^{\circ} \mathrm{C}$ for $25 \mathrm{~min}$ and allowed to cool. The roasted peanuts were then deshelled in a disc attrition mill and added to the roasted rice, and finally milled using a hammer mill (Brook Crompton Series 2000, Christy Hunt Agriculture Ltd., U. K.) until the desired texture was obtained. Flour from the soybeans was prepared by soaking the beans for $20 \mathrm{~min}$, drained and boiled in water for $30 \mathrm{~min}$. They were then dried in a hot air oven at $65^{\circ} \mathrm{C}$ to a final moisture content of about $8 \%$. The dried beans were deshelled in a disc attrition mill, winnowed, and milled into smooth flour. The dried milled powders were left to cool at room temperature, and mixed thoroughly using a KitchenAid mixer (Model 5KPM50, KitchenAid, St. Joseph, Mich., U. S. A.) at a slow speed for 2 min, collected in polyethylene bags, and stored at 3 to $5^{\circ} \mathrm{C}$ until used. The proportions of ingredients for the two mushroom cereal blend formulation are shown in Table 1.

For the Mushroom Orange-flesh Sweet Potato (MOFSP) mash, ingredients used included fresh mature Orange Fleshed Sweet Potato (OFSP) (Jewel CIP 440031), fish (herrings), tomato, onion and the mushroom (EM1 and PSCW). The OFSP, obtained through an accredited supplier, were cleaned, sorted, and freeze-dried (Ultra 35 super LE 210247, Virtis Company, Gardiner, NY., U.S.A.) and finally milled into flour that can pass through a 100-mesh sieve. The milled samples were packaged into polyethylene bags, and stored at 3 to $5^{\circ} \mathrm{C}$ until used. Flour from the fish (herrings) was prepared by roasting the fish and milled until smooth. The fresh tomato was also blanched for $2 \mathrm{~min}$, dried in the freeze dryer for 2 days and milled into smooth flour. Onion powder 
was prepared by freeze drying the fresh onion for 2 days and milled into a smooth powder. The dried milled powders of all the ingredients were left to cool at room temperature and thoroughly mixed using a KitchenAid mixer (Model 5KPM50, KitchenAid, St. Joseph, Mich., U. S. A.) at a slow speed for $2 \mathrm{~min}$. Two different MOFSP-mashes were formulated: One formulation had high percentage $(30 \%)$ of mushroom and the other formulation had low (5\%) percentage of mushroom. Proportions of the different ingredients are as shown in Table 1.

Table 1. Different mushroom-based food products formulated in the study.

\begin{tabular}{lllll}
\hline Formulation/Type of mushroom & \multicolumn{3}{l}{ Proportion of components (\%) } \\
\hline \multicolumn{2}{l}{ Cereal blend } & Mushroom powder & Rice-peanut flour & \\
1 & WeanieMix- EM1 & 10 & 77 & Soybean flour \\
2 & WeanieMix- PSCW & 10 & 77 & 13 \\
\multicolumn{2}{l}{ Orange fleshed sweet potato mash ${ }^{2}$} & Mushroom powder & OFSP flour & 13 \\
3 & Potato- High-EM1 & 30 & 45 & Fish powder \\
4 & Potato-Low-EM1 & 5 & 75 & 15 \\
5 & Potato-Low-PSCW & 30 & 45 & 10 \\
6 & Potato- High-PSCW & 5 & 75 & 10 \\
\hline
\end{tabular}

${ }^{1}$ Rice-peanut flour had $72 \%$ rice flour and $5 \%$ peanut

${ }^{2}$ Each OFSP-mash formulation had $5 \%$ tomato and $5 \%$ onion. A pinch of salt can be added during preparation depending on preference

\subsection{Investigating the Sensory Attributes of the Three Mushrooms Using QDA.}

Samples of the mushroom slurries were served to an 8member trained QDA panel for assessing of the sensory attributes. Samples were served in triplicate in a complete block randomized method with randomization done across session. The assessment was done in a sensory evaluation laboratory that conforms to ISO 8589 at the Department of Nutrition and Food Science, University of Ghana. The assessors developed individual vocabulary list with definitions to evaluate the samples (Table 2). References were provided to ensure that all assessors were in agreement with the descriptive terms that were generated. Additionally, the assessors rated the intensities of the samples for all the sensory properties on a $15 \mathrm{~mm}$ line intensity scale. [15]

\subsection{Focus Group Discussion (FGD) with Mothers and Caregivers on the Use of Mushrooms in Food Preparations for Children}

Three focus group discussions were conducted to understand perceptions and attitudes of mothers and care givers in general on the use of mushroom as ingredients in foods for children as well as sensory properties of mushrooms that were desirable in foods for the children. Thus in the FGD, the mothers and caregivers were given the chance to corroborate the findings of the sensory attributes of the three mushrooms as well as test the food concept prototypes made from them. Three focus groups discussions were conducted at three different locations; CSIR-Food Research Institute, Accra (Site 1 - Urban), Somanya Primary School (Site 2 - Rural) and, Department of Nutrition and Food Science (University of Ghana), Accra (Site 3 - Urban).

In each group, between 4 and 9 mothers and caregivers with children aged between 2 and 5 who consented to participate were included with a total number of 24 respondents between the three groups. The duration for each session was between 60 and 90 mins. A laddering approach was used for the interviewing process where follow up questions were based on responses given. At interview Site 2, an interpreter was used to translate from one local language (Krobo language) to another local language (Twi) before transcription into English. English was used as the language for communication at the remaining two sites. The same moderator conducted all the interviews. To assess the food concept prototypes, six mushroom-based food products (Table 1), as described earlier, were used during the taste sessions of the FGD. [17]

\subsection{Consumer-Liking Test Involving 83 Pre-school Children Aged 2-5 Years}

Based on the outcome of the FGD, two of the MCB and one of the MOFSP foods were selected for consumer-liking tests involving 83 pre-school children between 2 to 5 years old in the Yilo Krobo District in the Eastern Region of Ghana. These children were selected after permission was obtained from the District Education Service in Yilo Krobo District of Ghana and the parents.

Prior to the actual test, the selected pre-school children were trained over a period of two weeks to be able to hedonically score using coloured cards. For hedonic scale $1=$ dislike, a Red-coloured card was used. Similarly for the hedonic scale $2=$ neither dislike nor like, Blue Card and then for hedonic scale 3 = like, a Green Card was used. Through the promptings of the parents, the child lifted and displayed the card of his/her corresponding to the choice of scale as explained earlier and this was correspondingly recorded as the hedonic score for the child.

Following successful training of the preschool children, two additional weeks were used for the actual tests. One sample of food product was presented to the children in a day in a white bowl, labelled with a unique 3 -digit code and the food product was assessed using the developed 3-point hedonic scale scoring using the coloured cards.

\subsection{Data and Statistical Analyses}

Results for the QDA of the three mushrooms were analyzed by determining mean intensity scores for each attribute. A two-way analysis of variance (ANOVA) for the sample and assessor was done for each attribute using XL- 
STAT Pro Software Version 2011 (AddinSoft, France). Correlation between attributes was also done and a product map generated using principal components analysis XLStats. Analysis of variance was conducted on the means obtained for the consumer-liking tests using IBM SPSS version 20 (2011). Statistically significant attributes were further analyzed to see where the mean differences exist using Tukey's HSD at 95\% confidence interval. Finally, a ttest was used to compare differences in attributes rates for mushroom cereal blend (MCB) and mushroom orange flesh sweet potato (MOFSP) products.

\section{Results}

\subsection{Overall Sensory Profile of the Three Mushrooms}

Table 2 shows that the three mushroom, (Pleurotus ostreatus (EMI), Pleurotus sajor-caju (PSCW) and Auricularia ssp. (ART) could be described and differentiated from each other using 29 sensory attributes under the sensory modalities; appearance, aroma flavour, mouthfeel and aftereffects. Using principal component analyses, a product map as shown in Figure 1 was generated for the three mushrooms. As indicated, all the samples loaded on different spaces on the map. This meant there were distinctly different from each other. EMI was associated with the terms Ash colour, Brown, colour, Even appearance, Milled cereal aroma and Boiled crab flavour. PSCW was on the hand given descriptions such as Brown colour, Cream Colour, Fishy Aroma and Flour and Unami taste whilst PTR was given descriptors such as Herbal tea aroma, Cold black tea flavour, Bitter tastes and aftertaste, astringent afterfeel and chalky mouthfeel and aftertaste.

Table 2. List of descriptors and definitions for sensory properties of the three powdered mushrooms.

\begin{tabular}{|c|c|c|}
\hline Descriptors & Definition & Anchor \\
\hline \multicolumn{3}{|l|}{ Appearance } \\
\hline Frothy & Aggregation of bubbles on the top. & Not - very \\
\hline Precipitated & Dispersed nature of particles in water like a chalky suspension (stirring required). & Not - very \\
\hline Consistency & Degree of viscosity & Thin - thick \\
\hline Brown colour & Referring to the colour of local tom brown. & Not - very \\
\hline Cream colour & Referring to the colour of ideal milk. & Not - very \\
\hline Clarity* & Clarity of mixture- presence of suspended particles in the supernatant. & Clear - turbid \\
\hline Evenness* & Relating to the size and arrangement of particles of the sediment. & Smooth - rough \\
\hline \multicolumn{3}{|c|}{ 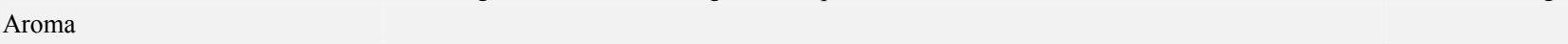 } \\
\hline Mushroom1 & Characteristic smell of umbrella mushroom- maxims & Not - very \\
\hline Mushroom2 & Characteristic smell of oyster mushroom like boiled cassava or fishy & Not - very \\
\hline Milled cereals & Characteristic smell of dried milled corn & Not - very \\
\hline Boiled crab & Characteristic smell of boiled crab water & Not - very \\
\hline Fishy & Characteristic smell like grouper & Not - very \\
\hline Herbal tea & Aroma associated with boiled green tea/ neem tree & Not - very \\
\hline Pungent & Sharp undefined smell & Not - very \\
\hline \multicolumn{3}{|l|}{ Flavour } \\
\hline Mushroom1 & Characteristic taste of umbrella mushroom- maxims & Not - very \\
\hline Mushroom2 & Characteristic taste of oyster mushroom like boiled cassava or fishy & Not - very \\
\hline Milled cereals & Characteristic taste of dried milled corn & Not - very \\
\hline Boiled crab & Characteristic taste of boiled crab water & Not - very \\
\hline Sea food & Characteristic taste like boiled squid & Not - very \\
\hline Fishy & Characteristic smell like grouper & Not - very \\
\hline Cold black tea & The taste and feel of cold black tea & Not - very \\
\hline Bitter & Basic taste & Not - very \\
\hline \multicolumn{3}{|c|}{ Mouthfeel and aftereffects } \\
\hline Chalky & Feel of particles lingering on the tongue & Not - very \\
\hline Umami & Basic taste & Not - very \\
\hline Astringent & Basic taste & Not - very \\
\hline
\end{tabular}

\subsection{Discriminating and Important Correlations of the Sensory Attributes}

Out of the 29 attributes, 17 of these showed statistically discriminating powers for the sample set and therefore may be considered as the key descriptive attributes, The colour descriptors, Ash colour, Brown Colour and Cream Colour, were adequate enough to discriminate between the appearance of the three mushrooms. Additional important appearance attributes that were important for distinguishing 
between them were Evenness, Consistency and Frothy. For aroma properties, important attributes that could be used to discriminate between the three mushrooms were Herbal Tea and Fishy whilst Cold black tea, Bitter, Milled Cereal and Fishy were the flavour descriptors established by the panel. For the mouthfeel and aftertaste properties, the discriminating descriptors were Chalky mouthfeel, and aftertaste, Bitter and Unami aftertaste and Astringent Afterfeel.

Two different types of mushroom aroma and flavour were described by the panel; mushroom 1 defined as umbrella mushroom and Mushroom 2 as Oyster mushroom. Although neither of these two terms were significant discriminators between the sample set, important correlations were observed. There was an association between Umbrella Mushroom Aroma (i.e. mushroom 1) and seafood aroma $(\mathrm{R}=$ 0.523 ) but this was poorly correlated with seafood flavour $(\mathrm{R}=0.309)$. Umbrella mushroom flavour was also not strongly correlated with seafood flavour $(\mathrm{R}=0.381)$. Conversely, oyster mushroom aroma was correlated with fishy aroma $(\mathrm{R}=0.543)$ as well as with fishy flavour $(\mathrm{R}=0.701)$. Again, oyster mushroom flavour was strongly correlated with fishy flavour $(\mathrm{R}=0.75)$. These observations suggest that oyster mushroom aroma follows through into the flavour and is strongly associated with the fishy aroma and flavour while umbrella mushroom aroma, which is associated with seafood aroma does not follow through into the flavour properties of the mushroom.

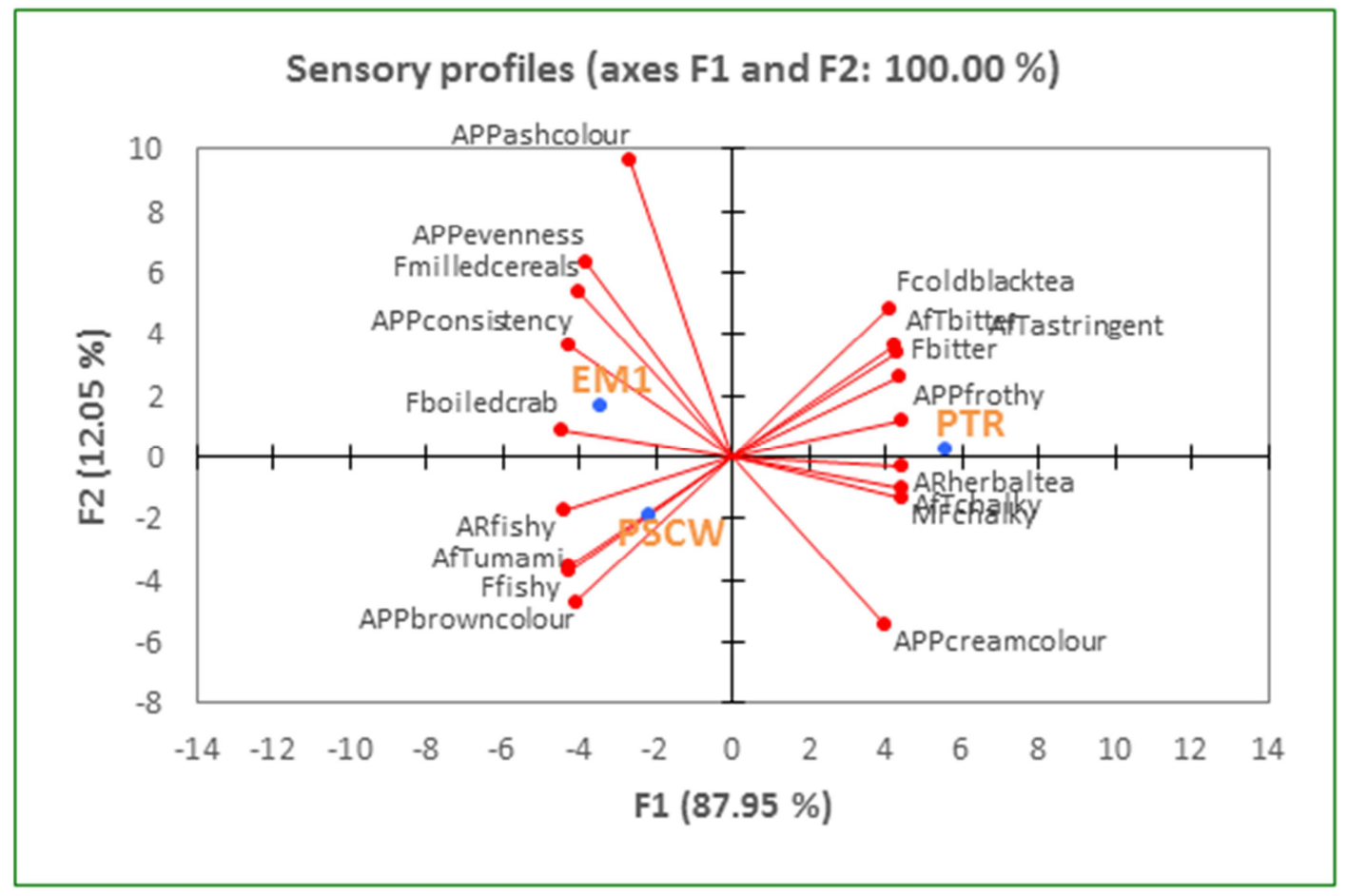

Figure 1. Product Map of the Three Edible Mushroom with associated Sensory Descriptors.

\subsection{Differences in the Sensory Attributes Between the Three Mushrooms: (Pleurotus ostreatus (EMI), Pleurotus Sajor-caju (PSCW) and Auricularia ssp. (ART)}

Two-way analysis of variance (ANOVA) with assessor - sample interaction was used to test differences between sample means for the different sensory attributes.. Overall, there was statistical significant difference between them for only 7 of the 29 sensory attributes. There was no statistical significant difference between the remaining attributes although significant assessor and interaction effects were detected for several attributes. Some important trends were however observed. These are shown further in the following.

\subsubsection{Differences in Appearance Attributes}

Figure 2 shows the appearance profile of the sensory mushrooms in a spider plot. There are distinct differences for colour properties; EM1 had the most intense Ash colour, none of the remaining two samples had Ash colour. All three samples had some variations of brown and cream colour. Although no statistical significant difference was found between mushrooms for cream colour, PTR had the highest intensity for this attribute and EM1 had the least intensity. A statistical significant difference between samples for brown colour was found with PTR showing the lowest intensity for this attribute. There was no statistical significant difference in brown colour between EM1 and PSWC. PTR was most frothy while EM1 was the most even and had the thickest consistency. 


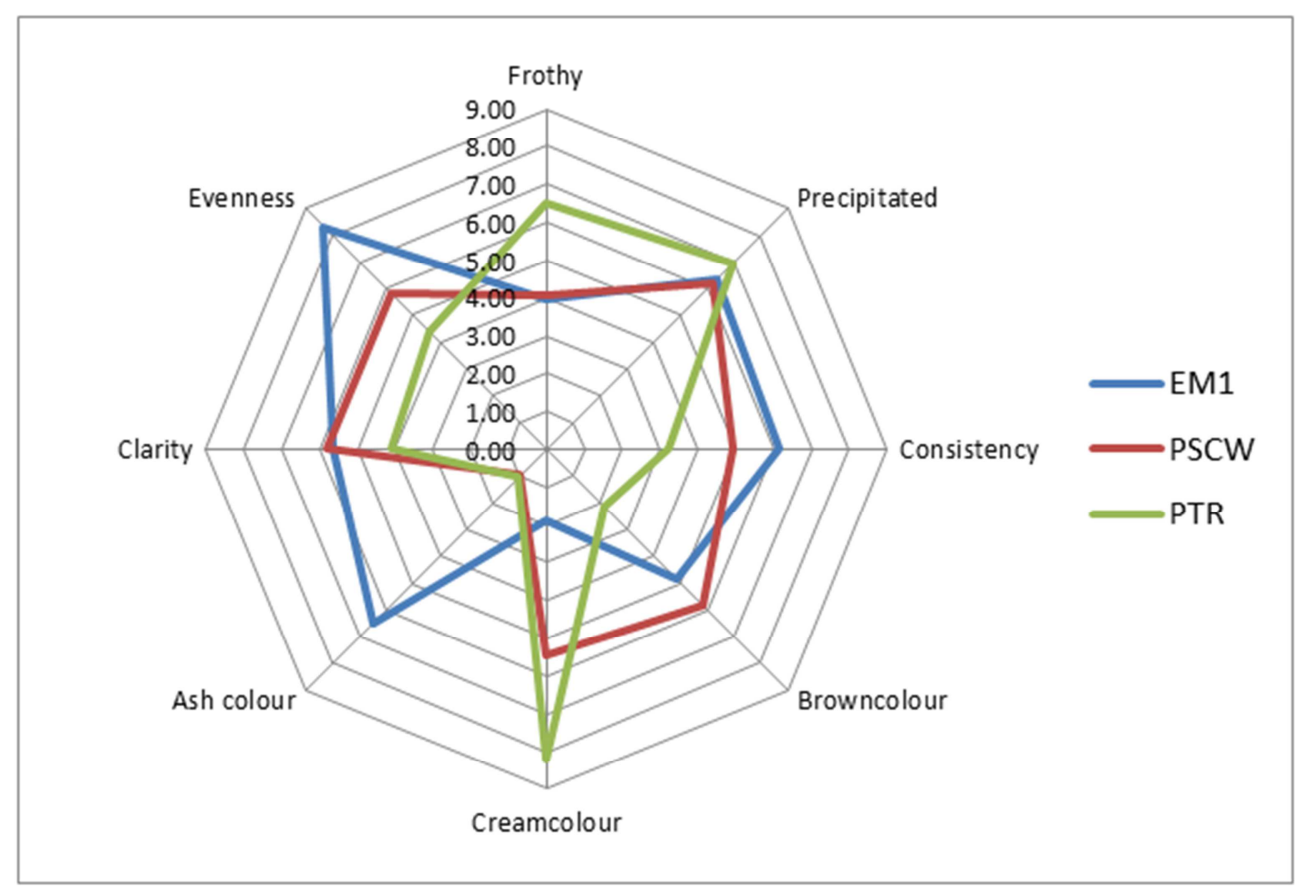

Figure 2. Spider plot showing appearance profile for the three mushrooms.

\subsubsection{Differences in Aroma Attributes}

Figure 3 shows the aroma profile for the three mushrooms in a spider plot. PTR was most intense and distinctly different to the EM1 and PSCW for herbal tea aroma. It also had the least fishy aroma. Although there was a trend suggesting that PTR was most pungent, this observation was not statistically significantly different. No other statistical significant differences were found. A trend suggesting that EM1 had umbrella mushroom aroma (mushroom1) and PSCW had oyster mushroom aroma (i.e. mushroom 2) was observed. No statistical significance difference was achieved for these two observations as there was a strong interaction effect between assessors and samples.

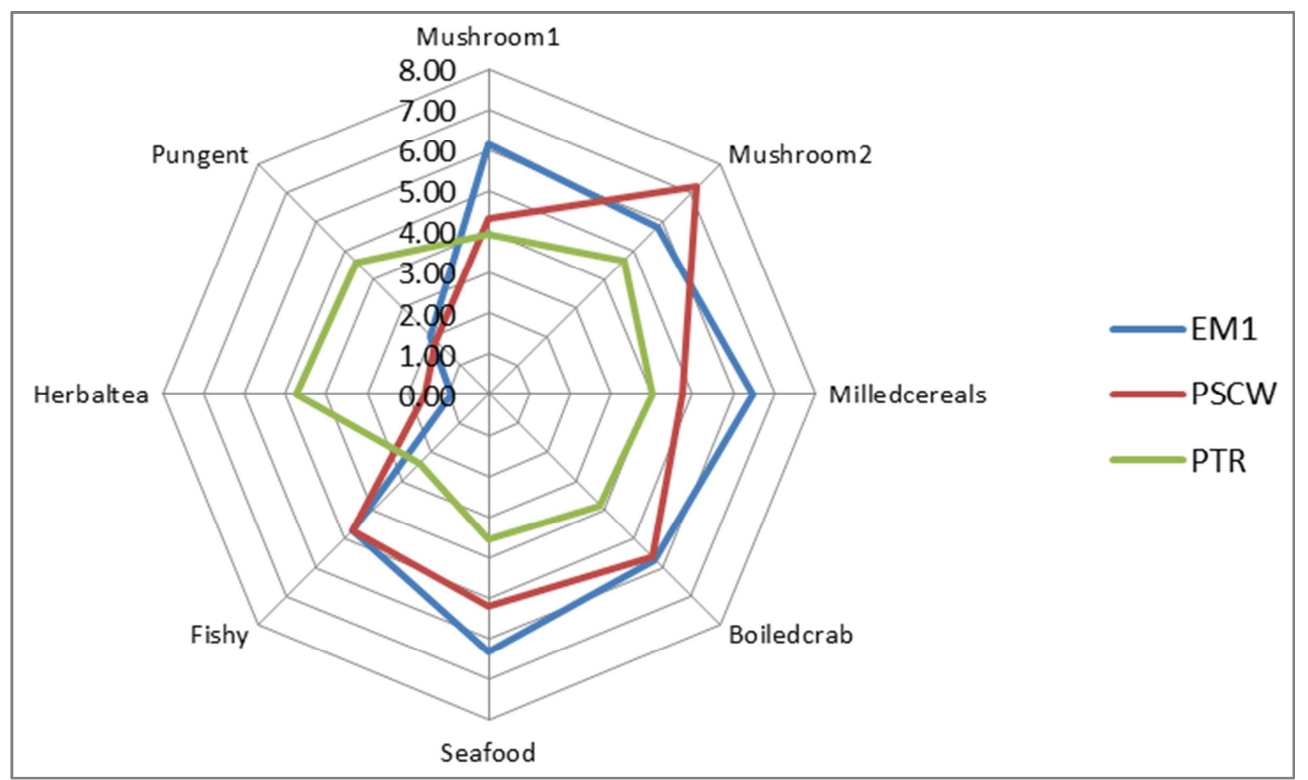

Figure 3. Spider plot showing aroma profile of the three mushrooms.

\subsubsection{Differences in Flavour Attributes}

The mean intensity scores for the samples are presented in a spider plot in Figure 4. There was a statistical significant difference between samples for cold black tea with PTR rated as the most intense for this attribute. It is important to note that cold black tea flavour was associated with herbal tea aroma $(\mathrm{R}=0.49)$. Although not a statistical significant difference, it is worth noting that PTR was also most bitter in taste. This observation may be due to an association between cold black tea and bitter taste $(\mathrm{R}=0.502)$ in this study. Other important trends that did not show statistical significant 
difference are that EM1 was most intense for mushroom 1 (umbrella mushroom), seafood, milled cereal and boiled crab flavours. PSCW was most intense for fishy and mushroom 2 (oyster mushroom) flavours.

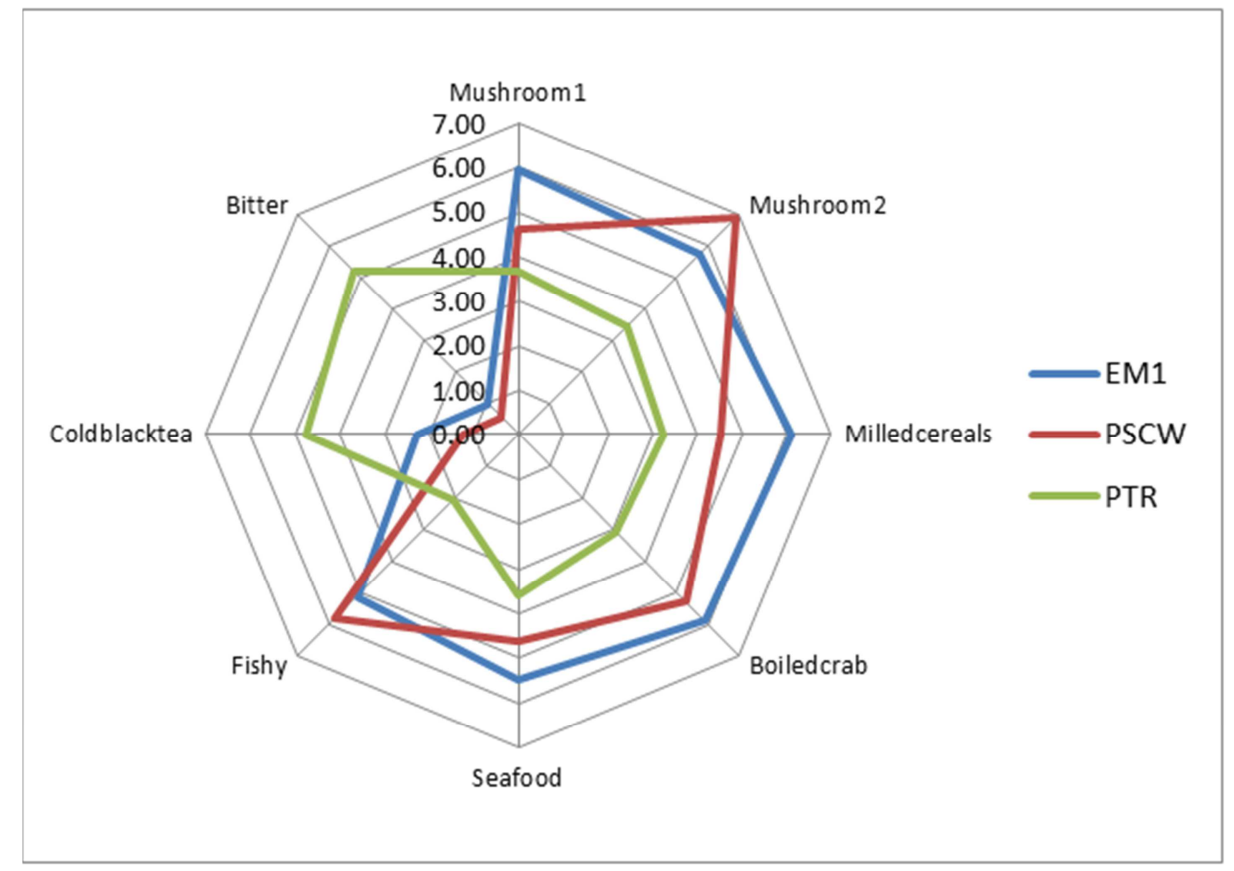

Figure 4. Spider plot showing flavour profile of the three mushrooms.

\subsubsection{Differences for Mouthfeel and Aftereffect Attributes}

PTR was distinctly different from the other two samples for mouthfeel and after effect properties as indicated in Figure 5. It was the chalkiest in mouthfeel, most bitter aftertaste and with most intense astringent afterfeel. Both EM1 and PSCW had more intense umami aftertaste than PTR.

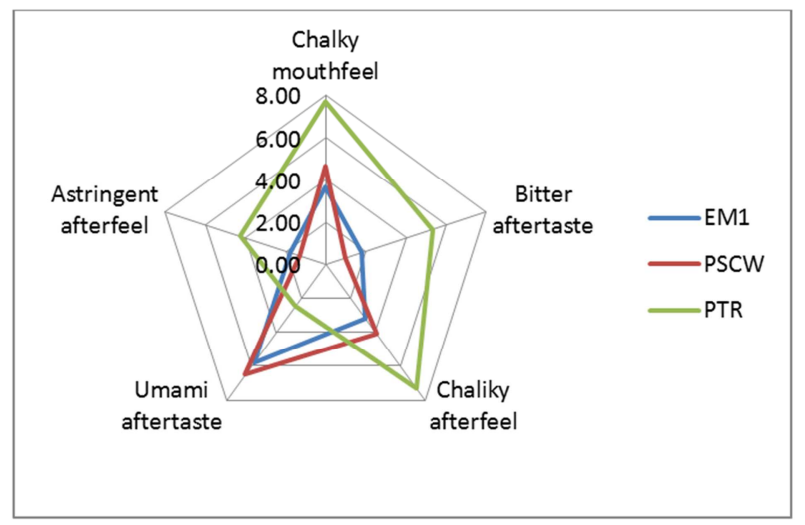

Figure 5. Mouthfeel and aftereffects of the three mushrooms.

\subsection{Results from the Focus Group Discussion}

Table 3 shows that the mothers and caregivers were able to detect most of the ingredients used in the preparations of the six mushroom products. They were able to make additional suggestions that helped improve the acceptability of the different mushroom-based food products by the children. Their suggestions clearly depended on the sensory properties established during the QDA.

\subsection{Results from the Consumer-Liking Tests Involving 83 Pre-school Children Aged 2-5 Years}

Table 4 shows that the overall acceptability of the mushroom cereal blend products was not significantly different from the cereal blend without mushroom. Also, the children liked the taste of the PSCW MOFSP-mash (2.07) more than that of the EM1 MOFSP-mash (1.16). Overall, Table 5 shows that the children preferred the mushroom cereal blend more than the mushroom orange-fleshed sweet potato products.

Table 3. Responses of Mothers and Caregivers to 6 Mushroom-based Products at the 3 Sites Used for the Focus Group Discussion.

\begin{tabular}{|c|c|c|c|c|}
\hline $\begin{array}{l}\text { Mushroom } \\
\text { Product Type }\end{array}$ & Site & $\begin{array}{l}\text { Perceived Ingredients by } \\
\text { Mothers and Care givers }\end{array}$ & Additional Comments by Mothers and Care givers & $\begin{array}{l}\text { Possible Relation to the } \\
\text { Determined Sensory Attributes } \\
\text { of the two selected mushrooms }\end{array}$ \\
\hline \multirow{3}{*}{$\begin{array}{l}\text { Weaniemix- } \\
\text { EM1 }\end{array}$} & 1 & $\begin{array}{l}\text { Maize, roasted maize flour and } \\
\text { mushroom }\end{array}$ & $\begin{array}{l}\text { Add sugar and milk to make more appealing. Salty and } \\
\text { can be used as breakfast cereal or evening meal }\end{array}$ & \multirow{3}{*}{$\begin{array}{l}\text { EM1 was characteristically ash in } \\
\text { colour with some brown colour } \\
\text { and will make a desirable } \\
\text { breakfast cereal }\end{array}$} \\
\hline & 2 & Maize, peanuts mushroom & $\begin{array}{l}\text { Add sugar and milk to make more appealing and can be } \\
\text { used as breakfast cereal or evening meal }\end{array}$ & \\
\hline & 3 & $\begin{array}{l}\text { Rice, maize, peanut, cowpea } \\
\text { mushrooms }\end{array}$ & $\begin{array}{l}\text { It is sweet. Children will like it because it can be used as } \\
\text { breakfast cereal }\end{array}$ & \\
\hline $\begin{array}{l}\text { Weaniemix- } \\
\text { PSCW }\end{array}$ & 1 & $\begin{array}{l}\text { Rice, mushroom, maize, peanut } \\
\text { and soybean }\end{array}$ & $\begin{array}{l}\text { Add sugar and milk to make more appealing. Children } \\
\text { will like it }\end{array}$ & $\begin{array}{l}\text { PSCW was cream coloured with } \\
\text { some brown colour and can be }\end{array}$ \\
\hline
\end{tabular}




\begin{tabular}{|c|c|c|c|c|}
\hline $\begin{array}{l}\text { Mushroom } \\
\text { Product Type }\end{array}$ & Site & $\begin{array}{l}\text { Perceived Ingredients by } \\
\text { Mothers and Care givers }\end{array}$ & Additional Comments by Mothers and Care givers & $\begin{array}{l}\text { Possible Relation to the } \\
\text { Determined Sensory Attributes } \\
\text { of the two selected mushrooms }\end{array}$ \\
\hline \multirow{5}{*}{$\begin{array}{l}\text { Potato- High } \\
\text { EM1 }\end{array}$} & 2 & $\begin{array}{l}\text { Maize, soybean, peanut, } \\
\text { mushroom, salty, savoury }\end{array}$ & $\begin{array}{l}\text { Our children will like it because it tastes just like } \\
\text { traditional weanimix and even better }\end{array}$ & \multirow[t]{2}{*}{$\begin{array}{l}\text { used interchangeably with EM1 } \\
\text { for a breakfast cereal }\end{array}$} \\
\hline & 3 & $\begin{array}{l}\text { Maize, soybean, peanut, } \\
\text { mushroom, salty, savoury }\end{array}$ & $\begin{array}{l}\text { Not too sweet. Respondents liked and felt their children } \\
\text { will like it }\end{array}$ & \\
\hline & 1 & $\begin{array}{l}\text { Mushroom, fish powder, } \\
\text { mashed, ripe and cooked } \\
\text { plantain and maize dough }\end{array}$ & $\begin{array}{l}\text { Appealing appearance, sweet and smooth texture. Nice } \\
\text { taste, but has a slight aftertaste }\end{array}$ & \multirow{3}{*}{$\begin{array}{l}\text { EM1 had an even consistency } \\
\text { that was thicker. It has a typical } \\
\text { umbrella mushroom aroma and } \\
\text { flavour }\end{array}$} \\
\hline & 2 & $\begin{array}{l}\text { Herrings, canned tomato puree, } \\
\text { palm oil, mushroom }\end{array}$ & $\begin{array}{l}\text { Tasty. More preferred to the alternate sample (Low } \\
\text { EM1) }\end{array}$ & \\
\hline & 3 & $\begin{array}{l}\text { Fish meal, vegetables like } \\
\text { carrots, mushroom }\end{array}$ & $\begin{array}{l}\text { Split opinion ( } 2 \text { respondents felt their children will like } \\
\text { it whilst another } 2 \text { did not agree) Umami flavor/ taste. } \\
\text { Sharp sweetness. Modify by increasing major } \\
\text { ingredients and reduce spices that give umami flavor. } \\
\text { Texture a little too rough. Good taste }\end{array}$ & \\
\hline \multirow{3}{*}{$\begin{array}{l}\text { Potato- Low } \\
\text { EM1 }\end{array}$} & 1 & $\begin{array}{l}\text { Taste like mashed, ripe and } \\
\text { cooked plantain and maize } \\
\text { dough, Yam, fish, shrimp, } \\
\text { mushroom sugar }\end{array}$ & $\begin{array}{l}\text { Though positive reactions from respondents, they have } \\
\text { however mixed opinions about child acceptance because } \\
\text { some say it is not like the normal soup the children } \\
\text { know of }\end{array}$ & \multirow{3}{*}{$\begin{array}{l}\text { Panelist wanted to taste the } \\
\text { typical umbrella mushroom } \\
\text { flavour and aroma which was not } \\
\text { in the low EM1 sample }\end{array}$} \\
\hline & 2 & $\begin{array}{l}\text { Taste like sweet yam, fish with } \\
\text { carrot and mushroom }\end{array}$ & $\begin{array}{l}\text { Respondents like the aroma but not the taste. Split } \\
\text { opinion on child acceptability. Generally less liked than } \\
\text { Potato- High EM1 }\end{array}$ & \\
\hline & 3 & $\begin{array}{l}\text { Fish meal, has vegetables like } \\
\text { carrots, Mushroom }\end{array}$ & $\begin{array}{l}\text { Less enthusiasm from respondents. Child acceptability: } \\
\text { Sweetness is good and also not too spicy }\end{array}$ & \\
\hline \multirow{3}{*}{$\begin{array}{l}\text { Potato-High } \\
\text { PSCW }\end{array}$} & 1 & $\begin{array}{l}\text { Herrings, mushrooms and } \\
\text { carrots }\end{array}$ & $\begin{array}{l}\text { Respondents suggested product should be improved for } \\
\text { children to accept it }\end{array}$ & \multirow{3}{*}{$\begin{array}{l}\text { PSCW has typical Oyster } \\
\text { mushroom aroma and flavour } \\
\text { which was strongly associated } \\
\text { with fishy aroma. } \\
\text { Fishy aroma has made it less } \\
\text { acceptable to caregivers }\end{array}$} \\
\hline & 2 & Peanut and herrings & $\begin{array}{l}\text { Less enthusiasm from respondents. One respondent } \\
\text { complained this product was so different from the } \\
\text { Potato- High EM1 and Potato- Low EM1 }\end{array}$ & \\
\hline & 3 & $\begin{array}{l}\text { Mushroom, fishmeal and } \\
\text { tomatoes }\end{array}$ & & \\
\hline \multirow{3}{*}{$\begin{array}{l}\text { Potato - Low } \\
\text { PSCW }\end{array}$} & 1 & $\begin{array}{l}\text { Mushroom, vegetables like } \\
\text { carrots, Fish meal }\end{array}$ & $\begin{array}{l}\text { Caregivers believe when the fishmeal is reduced their } \\
\text { children will accept it because they like the consistency }\end{array}$ & \multirow{3}{*}{$\begin{array}{l}\text { More acceptable than high PSCW } \\
\text { because it was reduced in this } \\
\text { product hence the fishy flavour } \\
\text { and aroma will also be reduced }\end{array}$} \\
\hline & 2 & $\begin{array}{l}\text { Taste like mashed, ripe and } \\
\text { cooked plantain and maize } \\
\text { dough, Yam, fish, shrimp, } \\
\text { mushroom sugar }\end{array}$ & $\begin{array}{l}\text { Caregivers said they liked the consistency and believe } \\
\text { their children will like it too }\end{array}$ & \\
\hline & 3 & $\begin{array}{l}\text { Mushroom, Fish meal and } \\
\text { tomatoes }\end{array}$ & $\begin{array}{l}\text { Child acceptability- Split opinions. Whilst some said the } \\
\text { consistent thickness will be acceptable to the children, } \\
\text { others felt fishy and sour tastes will not make it } \\
\text { acceptable }\end{array}$ & \\
\hline
\end{tabular}

Table 4. Mean acceptance scores of mushroom formulations.

\begin{tabular}{llll}
\hline & ${\text { Mean score for } \text { attributes }^{1}}$ & & \\
\hline Sample code & Appearance & Taste & Overall Acceptability \\
\hline Mushroom Cereal Blend Products & & & \\
EM1 & $2.93 \mathrm{a}^{2}$ & $2.87 \mathrm{~b}$ & $2.89 \mathrm{a}$ \\
PSCW & $2.87 \mathrm{a}$ & $2.78 \mathrm{ab}$ & $2.83 \mathrm{a}$ \\
No mushroom & $2.81 \mathrm{a}$ & $2.66 \mathrm{a}$ & $2.83 \mathrm{a}$ \\
Mushroom Orange Fleshed Sweet Potato Mash Products & & & $1.99 \mathrm{ab}$ \\
No mushroom & $2.3 \mathrm{a}$ & $1.55 \mathrm{a}$ & $1.94 \mathrm{a}$ \\
EM1 & $2.19 \mathrm{a}$ & $1.16 \mathrm{~b}$ & $2.20 \mathrm{~b}$ \\
PSCW & $2.13 \mathrm{a}$ & $2.07 \mathrm{c}$ & \\
\hline
\end{tabular}

${ }^{1}$ Sensory attributes were evaluated on a 3-point hedonic scale as follows: 1-dislike, 2- neither like nor dislike, 3-like; ${ }^{2}$ Mean in the same column followed by different alphabets are significantly different at $5 \%$ level of probability;.

Table 5. Comparing mean scores for attributes for mushroom cereal blend and MOFSP-mash.

\begin{tabular}{lllll}
\hline & \multicolumn{2}{l}{ Mean score for attributes $^{1}$} & & \\
\hline Sample code & Appearance & Taste & Overall Acceptability & p-value \\
\hline Mushroom Cereal Blend Products $(\mathrm{X} \pm \mathrm{SE})^{2}$ & $2.87 \pm 0.02$ & $2.77 \pm 0.32$ & $2.85 \pm 0.03$ & \multirow{2}{*}{0.05} \\
Mushroom orange fleshed sweet potato mash products $(\mathrm{X} \pm \mathrm{SE})$ & $2.21 \pm 0.04$ & $1.59 \pm 0.04$ & $2.04 \pm 0.05$ & \\
\hline
\end{tabular}

${ }^{1}$ Sensory attributes were evaluated on a 3-point hedonic scale as follows: 1-dislike, 2- neither like nor dislike, 3-like. ${ }^{2}$ Significance associated with student's ttest for attributes. 


\section{Discussion}

Children's eating patterns develop in the early social interactions surrounding feeding. Research has also shown that parents significantly influence their children's early experiences with food and eating habits. Hendy et al (2013) have also explained that mothers and caregivers act as influential socialization agents in shaping children's acceptance of any range of foods presented during their formative period. The results from both our focus groups survey as well as the consumer-liking tests all showed that the target children of the mothers and caregivers in this study ate the same foods as the whole family with slight modifications made to the sensory properties of the foods they eat to help with adaptation to cultural foods. These studies support our observations of the mothers and caregivers in this study who liked the two products and indicated that they will feed their children the mushroom cereal blend as breakfast and the mushroom potato mash as lunch (Table 3).

Parents select the foods of the family diet, serve as models of eating that children learn to emulate, and use feeding practices to encourage the development of culturally appropriate eating patterns and behaviours in children. Children's intake of particular foods is influenced not only by the types of foods present in the home, but also by the amount of those foods available to them. In our current study, mothers and caregivers explained that although mushrooms are suitable ingredients as food, a major limitation for its use as an ingredient is that it is seasonal in Ghana. Research indicates that the extent to which fruits and vegetables are present and readily available and accessible in the home correlates positively with the level of consumption in schoolage children. Thus, if mushrooms are available for the home, the level of consumption in the target age group could also increase for the nutritional benefits of the mushroom to be realized.

According to the focus group discussions, most mothers and caretakers were willing to feed their children the two products (Table 3). Wilcock et al (2003) and Guinard (2000) have demonstrated that food consumption behaviour is an index that assesses attitudes towards a food product.[23], A person may like the product but may not be willing to consume it on a regular basis or in large amounts. The focus group discussion revealed that young children in the target areas eat family foods, they do not like to feel discriminated from eating what the whole family is eating. Children's preferences are considered in terms of the sensory properties of the food particularly the level of spiciness (degree of heat or pungency from chilli pepper), even though some children can eat very spicy foods. The sensory properties of food that are important to children's food acceptability are the appearance (colourful), taste, sweet, flavour, spice level and texture (soft). From the focus group discussion, caregivers in the urban area liked the sweetness of the orange flesh sweet potatoe products and agreed that it is possible that children in urban regions will have a higher threshold for sweetness acceptance than children in rural areas.

Normal food may be defined as typical of the food prepared for the family. The form in which mushroom is incorporated in foods for children will influence its acceptance. This means for children in the target group, incorporating mushrooms into foods will be most acceptable by processing them so as not to be visible. Caregivers of the target age group may be able to tell if children like a particular food based on prior experience of the food by the child. In some instances the sensory properties of the food may be a cue to determine the acceptance of the food (particularly based on the level of spiciness).

The focus group results suggest that the cereal blend product with mushroom was most acceptable to caregivers although further studies are needed to confirm than the orange fleshed sweet potato products with mushrooms (Table 3 ). The cereal blend products were considered more normal foods by caregivers and thought to be more acceptable by the target children. The consumer acceptance test with the children confirmed this (Table 4). The attributes for the cereal blend products were significantly $(p \leq 0.05)$ more acceptable to the children than the attributes for the MOFSPmash products (Table 5). There was mixed level of acceptance and mixed opinions on child acceptance for the MOFSP-mash products. Nonetheless, the PSCW MOFSPmash products had a more positive response from the caregivers compared with the EM1 MOFSP-mash product (Table 3). The consumer acceptability test with the children showed that the children liked the taste of the PSCW MOFSP-mash than the taste of the EM1 MOFSP-mash (Table 4).

\section{Conclusions}

This study revealed that edible mushrooms $P$. ostreatus, $P$. sajor-caju and Auricularia spp have distinct sensory parameters of appearance, mouthfeel and aftertaste; even though the aroma and flavour profiles of the first two were comparable.

In particular, P. ostreatus, and P. sajor-caju can be used as flavorants in developing mushroom-based food products for pre-school children aged between 2 and 5. P. ostreatus is suitable for fish or savory-flavoured products whilst $P$. sajorcaju is good nutty-flavoured products.

Both mushrooms were successfully used in producing a cereal-fortified mushroom and an orange flesh yellow potato flour fortified mushroom foods products for these children.

\section{Conflicts of Interest}

The authors declare that they have no conflicts of interest.

\section{Acknowledgements}

We acknowledge USAID-Partnerships for Enhanced 
Engagement in Research (PEER) Science project for supporting the data collection at the Center for Advanced Functional Foods Research and Entrepreneurship, Department of Food Science and Technology at the Ohio State University.

\section{References}

[1] Garcia-Lafuentea A., Carlos Moro, Ana Villares, Eva Guillamon, Mauricio A. Rostagno, Matilde D'Arrigo and Jose Alfredo Martinez (2011). Mushrooms as a Source of AntiInflammatory Agents. Anti-Inflammatory \& Anti-Allergy Agents in Medicinal Chemistry, 9(2): 125-141.

[2] Smith, J. E., Rowan, N. J. and Sullivan, R. (2002) Medicinal mushrooms: a rapidly developing area of biotechnology for cancer therapy and other bioactivities. Biotechnology Letters. 24 (22) $1839-1845$.

[3] Apetorgbor, A. K., Dzomeku, M., Apetorgbor, M. (2013) Growth factors and cultivation of Pleurotus tuber-regium on selected plant wastes. International Food Research Journal 20(6):3387-33943

[4] Dzomeku, M., Apetorgbor, A. K., Apetorgbor, M. M and Obodai, M. (2014). Ailments and Application of Pleurotus tuber-regium (PTR) among indigenes of two regions in Ghana. Scientia Agriculturea 3(3), 2014: 129-132. www.pscipub.com/SA.

[5] Obodai, M., Ferreira, I C. F. R., Fernandes, Â, Barros, L., Mensah, D, L, Matilda Dzomeku, M. Urben, A. F., Prempeh, J and Takli, R. K. Takli (2014). Evaluation of the Chemical and Antioxidant Properties of Wild and Cultivated Mushrooms of Ghana. Molecules 19(12), 19532-19548; doi: 10. 3390/molecules 191219532 .

[6] Rukhsana Amin, Md. Zakirul Islam, Moushumi Sen, Sohely Nazneen Eva, Suha Jesmin, Shamsun Nahar (2012). AntiObesity Effect of Mushroom (Ganoderma Lucidum)on Experimentally Induced Obese Rats. AKMMC J 2012: 3(2): $11-14$.

[7] World Health Organization (2012). World Health Statistics 2012.

[8] World Health Organization (2003). The World Health Report: 2003: Shaping the future.

[9] Agbozo, F., Atito, P and Abubakari, A. (2016). Malnutrition and associated factors in children: a comparative study between public and private schools in Hohoe Municipality. BMC Nutrition. https//doi.org/10.1186/s40795-016-0073-7

[10] Obodai, M and Odamtten, G. T. (2011) Phenology of mycoflora and some physical and organic composition of agricultural wastes in the cultivation of the mushroom Volvariella volvacea. 212.47.242.17:8000/jspui/handle/123456789/784

[11] Briefel, R. R, Crepinsek, M. K., Cabili, R. D, Wilson, A and Gleasu, P. M. (2009) School food environments and practices affect dietary behaviours of US Public School Children. Journal of Academy of Nutrition and Dietetics, 109, 2, 91-107.
[12] Knai, C. Pomerleau, J. Lock, K and McKee, M, (2006). Getting children to eat more fruit and vegetables: A systematic review. Preventive Medicine. 42(2) 85 -95.

[13] Michaelson, K. F., Hippe, C., Roos, N., Kastel, P., Stougaard, M., Lotte, L., Molgaard, C., Girma, T., and Friis, H. (2009) Choice of foods and ingredients for malnourished children 6 months to 5 years of age. Food and Nutrition. Bul. 30, 3,343404

[14] Serrem, C. A. de Kock, H. L., Taylor, J. R. N. (2011) Nutritional quality, sensory quality and consumer acceptability of sorghum and bread wheat biscuits fortified with defatted soyflour. International Journal of Food Science and Technology, 46,1,74-83.

[15] Hettiarachchi, C. A. and Illeperuma, D. C. K. (2015). Developing a trained sensory panel for comparison of different brands of vanilla ice cream using descriptive sensory analysis. Journal of the National Science Foundation of Sri Lanka. 43(1), 45 -55.

[16] Grunert, K. G., Bech-Larson, T. Bredahl, L (2000). Three issues in consumer quality perception and acceptance of dairy products. International Dairy Journal. 10(8) 575 -584.

[17] Barnertt, V. (2002) Sample survey principles and methods. Arnold, London.

[18] Smith, E. V. (2002) Understanding Rasch measurement: Detecting and evaluating the impact of multi-dimensionality using item fit statistics and principal component analysis. Journal of Applied Measurement. 3(2), 205 -231.

[19] Young, E. M., Fors, S. W. and Hayes, D. M. (2004). Associations between perceived parent behaviours and middle school student fruit and vegetable consumption. Journal of Nutrition Education and Behavior, 36, (1), 1-56.

[20] Hendy, H. M., Seiverling, L., Lukens, C. T. and Williams, K. E (2013) Brief assessment of mealtime behaviour in children: Psychometrics and association with child characteristics and parent responses. Journal of Children's Health Care. 42(1) https://doi.org/10.1080/02739615.2013.753799

[21] Rhee, K. E. Lumeng, J. C., Danielle, P., Appugliese, D. P. Kaciroti, N. and Bradley, R. H. (2006) Parenting styles and overweight status in first grade. Pediatrics. 117(6), 2047 2054.

[22] Cullen, K. W., Baranowski, T., Rittenberry, L. and Olvera, N. (2000) Social-environmental influences on children's diets: results from focus groups with Africa-, Euro- and MexicanAmerican children and their parents. Health Education Research. 15, (5), $581-590$.

[23] Wilcock, A., Pun, M., Khanona, J. and Aung, M (2003) Consumer attitudes, knowledge and behaviour: a review of food safety issues. Trends in Food Science and Technology, 15 (2) $56-66$.

[24] Guinard, J-X. (2000) Sensory and consumer testing with children. Trends in Food Science and Technology, 11(8) 273 283.

[25] Ludy, M-J., and Mattes, R. D. (2012). Comparison of sensory, physiological, personality and cultural attributes in regular spicy food users and non-users. Appetite. 58 (1) 19 -27. 